\title{
El imaginario flamenco americano: Aura y Kitsch en la escena transnacional ${ }^{1}$
}

\author{
SUSANA ASENSIO \\ Área de Cultura Científica \\ CSIC. Madrid
}

\section{RESUMEN}

Las continuas transformaciones sufridas por el flamenco han estado siempre relacionadas con su interacción con innumerables tradiciones. Lo que una vez fue un fenómeno local, aunque híbrido desde su origen, se convierte en un fenómeno musical camaleónico, capaz de producir fenómenos nuevos al tiempo que sigue manteniendo su personalidad distintiva. El movimiento transnacional del flamenco comenzó ya en el siglo XIX, aunque podemos considerar que su viaje a los Estados Unidos es el que más relevancia ha tenido. Allí, sin embargo, los artistas desarrollaron sus carreras no sólo aislados del entorno sociocultural flamenco, sino también de la cultura popular americana. Su aislamiento fue doble y así los artistas americanos desarrollaron maneras específicas de interpretar y experienciar el flamenco representativas del Kitsch más contemporáneo.

Palabras clave: Flamenco, Culturas transnacionales, Kitsch, Aura.

\section{SUMMARY}

The continuous transformations suffered by flamenco have always been related to its interactions with many other traditions. What once was a local experience, although hybrid from its origins, was transformed into a chameleonic musical phenomenon able to produce new development while conserving a characteristic personality. The transnational flamenco progress started around the end of $19^{\text {th }}$ century. It is considered that its trips to America, especially those to the United States, were the most relevant to the phenomenon. However, flamenco artists developed their careers detached from its socio-cultural environment - and even from American cultures- in the new settings. Their isolation was twofold and favored specific ways to perform and experience flamenco. This new expansion gave transnational flamenco a distinctive and contemporary Kitsch touch.

Key Words: Flamenco, Transnational cultures, Kitsch, Aura.

\footnotetext{
${ }^{1}$ Este trabajo ha sido subvencionado por una beca post-doctoral de la Comisión Fulbright (Columbia University 1999-2000, New York University 2000-2001), así como por el Departamento de Estudios Españoles de New York University (2001-2002). La investigación ha recibido ayudas también del "King Juan Carlos I of Spain Center" de Nueva York, así como del «Program for Cultural Cooperation between Spain's Ministry of Education, Culture and Sports and United States Universities" de Minneápolis (ambos en 2001).
}

RDTP, LIX, 2 (2004): 145-159 
If a souvenir is the commodification of a remembrance, Kitsch is the commodification of the souvenir.

(Olalquiaga 1998: 80)

An interregnum, Kitsch [is] half dream and half reality, all memory and desire.

(Ibid.: 97)

La actitud predominante hacia el flamenco en la escena internacional es de fascinación y curiosidad. El flamenco provee imágenes exóticas de culturas antiguas y misteriosas, y también poderosos fetiches para el consumo, especialmente las impresiones que las bailaoras producen. También es el flamenco fuente de extraños souvenirs, imposibles decoraciones en locales de comidas híbridas - transnacionales- y actuaciones de élite para audiencias exclusivas. Es una fuente inagotable de reflexión para aficionados, intelectuales y académicos. Un fenómeno cultural polidimensional, capaz de encajar en los más impensables entornos fuera de su terruño -desde Sudáfrica a Tokio- y que consigue dotar a estos entornos del color, pintoresco y cosmopolita a la vez, de un modo de vida centenario y plenamente contemporáneo. El flamenco representa, como diría Baudrillard, un espectáculo del exceso, una "representación de la obscenidad" (1994: 17), al desvelar privacidades culturales en espacios públicos destinados al consumo de estos secretos.

Pero el flamenco también es capaz de absorber casi cualquier elemento musical y sonoro, y de incorporarlo a su propio discurso espectacular, dando lugar a mezclas y fusiones impredecibles. Y también es mimético: se hace simulación cuando habla de simulación y seduce cuando habla de seducción; utiliza las mismas estrategias de las ideas que representa (Baudrillard 1994: 82). Las continuas transformaciones sufridas y establecidas por el flamenco durante el siglo $\mathrm{xx}$, especialmente en la era de la globalización, implican que la fusión e interacción con innumerables tradiciones se ha hecho consciente y explícita. Lo que una vez fue un fenómeno local -aunque híbrido desde su origen - se convierte en un fenómeno musical camaleónico, capaz de transformarse insospechadamente y de producir fenómenos nuevos, al tiempo que sigue manteniendo su personalidad distintiva.

\section{LA ESCENA TRANSNACIONAL Y EL INICIO DE LA ESQUIZOFRENIA FLAMENCA}

Según McGrew (1996: 470), el término globalización alude a "la multiplicidad de conexiones e interconexiones que transcienden los estados- 
nación (y por tanto, las sociedades) y que construyen el mundo moderno. [La globalización] define un proceso a través del cual los eventos, decisiones y actividades que tienen lugar en una parte del mundo, pueden tener consecuencias significantes para individuos y comunidades en lugares muy distantes". Algunos autores prefieren hablar de "ecumene" (Kroeber 1945, cit. en Hannerz 1998: 21), término que designaba el mundo conocido para los griegos, ya que la dispersión de información es desigual y no afecta de la misma forma a todos los lugares, gentes y culturas. Hannerz encuentra el término "transnacional" más adecuado, porque según él es "más humilde y a menudo más adecuado para fenómenos que pueden tener una escala y distribución variables" (1998: 20). Canclini hará hincapié en la desigualdad y las paradojas de esta globalización, no tanto para invalidar el término, sino para poner de manifiesto su radical diferencia en relación con distintos contextos, su característica de "imaginada", de teoría que propicia prácticas desiguales (GarcíaCanclini 2000).

El movimiento del flamenco desde sus orígenes rurales andaluces a su actual condición transnacional y cosmopolita comenzó ya en el siglo xIX. Se sabe que cantantes y guitarristas flamencos, aún no considerados como "artistas", tenían reuniones informales en tabernas ya antes del siglo XIX. A veces su actuación iba acompañada de baile realizado por "mujeres públicas" o prostitutas. Estas actividades y actuaciones informales en tabernas y locales privados andaluces establecieron el inicio del ulterior desarrollo del flamenco, que en otros lugares sería interpretado en cafés cantantes (Washabaugh 1996: 33), y cuya edad de oro duraría aproximadamente desde 1860 a 1910. Los Cafés cantantes eran lugares públicos, cafeterías al estilo del XIX, donde una variedad de espectáculos se ofrecían para entretener a un público fundamentalmente masculino. Aunque estos cafés inicialmente atrajeron cantantes, pronto también el baile comenzó a formar parte de los números musicales y así se estableció como elemento espectacular por excelencia de las actuaciones. La combinación de cante y baile resultó muy exitosa, atrajo un numeroso público a los cafés - desde trabajadores a hombres de negocios, intelectuales y turistas- y, como resultado, los intérpretes comenzaron a ser pagados por los propietarios de los establecimientos y a transformarse en artistas.

El flamenco floreció como fenómeno comercial en estos Cafés cantantes. El conjunto inicial de voz y guitarra se transformó con la incorporación del baile en un show de espectacularidad creciente, con trajes elaborados, danzas coreografiadas y canciones compuestas especialmente para el público de los cafés. Desde estos escenarios iniciales, el flamenco se movió, casi de manera natural, a los teatros. Antonio Chacón, un payo 
nacido en 1869 , y considerado uno de los más grandes cantantes de su tiempo a pesar de no ser gitano, fue el primer artista reconocido que introdujo el flamenco en el teatro, quizás por su condición de payo. En los años previos al inicio de la Primera Guerra Mundial (Woodall 1992: 145-146) Chacón trazaría el camino que seguirían los futuros cantantes y bailaores, tanto gitanos como payos.

Con la introducción del flamenco en los espacios sagrados y espectaculares de la "alta cultura", mientras aún seguía siendo vivido e interpretado en sus entornos familiares tradicionales, se inició la esquizofrenia del mundo flamenco. La misma denominación de "flamenco" comenzó a ser utilizada para designar ambos entornos: el de las tradiciones musicales y culturales ancestrales (es decir, el flamenco como expresión cultural y modo de vida), y el nuevo producto creado para ser comercializado (el flamenco de escenario, el flamenco viajero y, posteriormente, transnacional). Más tarde, el éxito del fenómeno teatral sobrepasó las fronteras andaluzas y las conexiones entre la tradición inicial y los varios desarrollos nacionales y transnacionales se multiplicaron, dando lugar a una variedad de formas, productos y procesos. En la actualidad, no cabe duda de que ambos fenómenos, el tradicional y el transnacional, son importantes para la vida del flamenco, pero ¿hasta qué punto pueden ser considerados como parte del mismo fenómeno eventos tan dispares como las actuaciones flamencas en un restaurante en Nueva York, las que tienen lugar en el Teatro Real de Madrid, las que se siguen celebrando en entornos privados de aficionados dentro y fuera de España, y aquellas consideradas como representativas por las autoridades oficiales en diferentes lugares?, ¿qué decir de las músicas de Camarón de la Isla y Ketama, los bailes de Joaquín Cortés y Carlota Santana, las fusiones de Chano Domínguez y La Barbería del Sur?, ¿de dónde obtienen los diferentes productos catalogados como "flamencos" la unidad para ser considerados parte del mismo fenómeno?

Mi propuesta es que entre ellos existe una "diferencia sincronizada", es decir, que son capaces de hacer circular y apoyar discursos diferentes y en ocasiones contradictorios, mientras forman parte del mismo fenómeno general (Olalquiaga 1992: 38). Esta "diferencia sincronizada" es uno de los rasgos principales de las culturas urbanas contemporáneas y viene dada, entre otras razones, por la simultaneidad diacrónica y sincrónica que la dimensión transnacional imprime: diferentes transformaciones se dan simultáneamente en el flamenco, y fenómenos similares se distribuyen por innumerables lugares a un tiempo. Así, se establecen paralelismos claros entre fenómenos absolutamente diferentes.

Entiendo el calificativo "transnacional" en este caso como evocativo de su carácter viajero y cosmopolita. Este carácter es el que posibilita que se 
diluyan y desaparezcan las originales fronteras administrativas del triángulo Sevilla-Jerez-Utrera, núcleo originario en cuanto a producción, difusión y recepción del flamenco ${ }^{2}$. Y también es este carácter transnacional el que favorece la disolución de los límites entre géneros, formas y contenidos, posibilitando la fusión, el mestizaje y la hibridación.

Al mismo tiempo, es la "transnacionalidad" del flamenco, su capacidad de viajar y ser adoptado por otras culturas, su constante movimiento y descentralización, la que ha generado los cánones referenciales de la tradición que sirven de freno y crítica por los más puristas. El punto de vista más común entre ellos es que la "excesiva libertad" con la que se mueve y es transformado el flamenco, especialmente con los nuevos medios técnicos y electrónicos, puede desembocar en su "desesencialización". La "esencia" flamenca, cualquiera que sea su definición, es la que mantiene el misterio del fenómeno y hace posible así no sólo su mantenimiento como tradición viva, sino también su exitosa comercialización bajo una etiqueta común. Básicamente vendría dada por un origen cultural, geográfico y referencial común que es asociado por defecto a todos los fenómenos que utilizan la etiqueta de "flamenco". No hemos de olvidar que cuando el concepto de "autenticidad" es asumido como "genuinidad" o "pureza de formas", la hibridación es vista como un proceso desnaturalizador y por tanto, potencialmente dañino para la conservación de la tradición musical. Sin embargo, cuando este mismo concepto se asocia a la mera idea de "origen común", el mestizaje no resulta tan amenazador.

\section{EL FLAMENCO Y NUEVA YORK}

De entre todos los viajes que el flamenco ha hecho por diferentes países, podemos considerar que su viaje a los Estados Unidos, primero a la ciudad de Nueva York, y luego a muchas otras de la costa oeste y del

\footnotetext{
${ }^{2}$ Este triángulo aún sirve de referencia para la historia y la mitología del flamenco. De Sevilla no será necesario hablar por ser reconocido como el núcleo más prolífico de figuras internacionalmente reconocidas. En cuanto a Jerez y Utrera (y en menor medida otros lugares como Alcalá de Guadaira y Lebrija, o Morón de la Frontera), se ganaron un lugar preferencial en la historia del cante por los numerosos nombres de artistas reconocidos en el flamenco que nacieron o se desarrollaron artísticamente en ellas. Recordemos que el primer nombre del que hay memoria escrita en la historia del cante flamenco, el Tío Luis el de la Juliana, es situado por Manuel Machado y Álvarez en el ultimo tercio del XVIII en Jerez, aunque aún no se sepa a ciencia cierta si fue un personaje real o construido por el mito popular. Cf. Grande (1979), Machado y Álvarez (1975, 1981), Álvarez Caballero (1981), Caballero Bonald (1997).
} 
sur, es el que más relevancia ha tenido para el fenómeno flamenco y sus desarrollos en España durante la primera mitad del siglo $\mathrm{xx}^{3}$.

El flamenco llegó a los Estados Unidos en un principio siguiendo a los emigrantes. Por un lado, la difícil situación de España en la época de entresiglos provocó masivas emigraciones de trabajadores que intentaban huir de la miseria. En los primeros años del siglo $\mathrm{XX}$, varias comunidades españolas se establecieron en Nueva York, recreando sus costumbres y tradiciones en privado en el entorno familiar, y en público en los llamados "clubes sociales", los cuáles en ocasiones ofrecían juergas flamencas los sábados por la noche. Estos clubes fueron establecidos con el propósito de ofrecer a la comunidad española un lugar para encontrarse y charlar, y también para acoger eventos sociales. La mayor parte de ellos abrieron en los primeros años 20, y duraron aproximadamente hasta el inicio de la Segunda Guerra Mundial. La población española que los frecuentaba estaba compuesta básicamente por trabajadores de extracción popular. De entre estos trabajadores, algunos eran artistas, y la mayoría de ellos entraron al país vía Nueva York. El desarrollo de estos clubes fue en incremento con motivo del inicio de la Guerra Civil española en 1936, ya que la simpatía y apoyo mostrados por los americanos hicieron que muchos más españoles pensaran en viajar a Norteamérica, y especialmente a las grandes ciudades (Fernández-Shaw 1987).

Por otro lado, el flamenco disfrutó de gran éxito en América desde los años 1930 a los 1960, gracias a las actuaciones y turnés de famosos artistas flamencos españoles en los teatros, especialmente La Argentina, Vicente Escudero y Carmen Amaya (Mercé 2000; Escudero 1947; Bois 1994). Sol Hurok, el famoso empresario que hizo posible el éxito internacional de Carmen Amaya en los Estados Unidos, trajo también otras muchas compañías y figuras flamencas a Broadway y las patrocinó en sus giras artísticas. A la vez, diferentes clubes nocturnos a lo largo de todo el país contaban con actuaciones flamencas, y más tarde la televisión llevó el flamenco a los hogares de aquellos que aún no lo conocían. De esta manera, durante algunas décadas, y especialmente a lo largo de los años 50 y 60 , parecía que el flamenco estaba en todas partes. Como resultado, un provechoso mercado fue establecido para comercializar el nuevo fenómeno en América (Draegin 1978).

\footnotetext{
3 A pesar de que hoy en día quizá los escenarios de flamenco americano más renombrados se sitúen en la costa oeste (California) y los estados sureños (especialmente Nuevo México), hasta bien avanzado el siglo XX y gracias a las giras de los primeros artistas por la costa este, fue Nueva York el punto de producción y difusión flamenca más activo.
} 
Aunque Hurok recibió numerosas críticas por traer artistas extranjeros a los Estados Unidos, los americanos simpatizaron rápidamente con la situación de España durante la Guerra Civil, y se dejaron cautivar por el flamenco (Robinson 1994) de los artistas españoles primero, y de los americanos después. Hurok trajo en varias ocasiones a Vicente Escudero y a Carmen Amaya, y sus éxitos se hicieron más notorios en cuanto que contrastaban con los fallidos proyectos destinados desde la oficialidad norteamericana para promover danzas alternativas en los Estados Unidos durante el periodo de entreguerras. A diferencia de estos proyectos, que estaban pensados para promover y difundir la parte más intelectual de la danza, las actuaciones de flamenco - de promoción privada y sin intención alguna de intelectualizar el fenómeno- fueron inmensamente populares, y de ello tomaron buena nota las administraciones públicas pasado el tiempo. La clave de su éxito residía en su diferencia y su exotismo, en la capacidad del flamenco de transportar al público a un mundo radicalmente distinto y de liberarlo con ello de sus problemas cotidianos durante el tiempo que duraba la actuación.

Comenzando con bailaores como Vicente Escudero y La Argentina, los pioneros en América, las actuaciones públicas de flamenco en los primeros años 30 sentaron las bases para que otros artistas pudieran venir y triunfar, especialmente Carmen Amaya y el guitarrista Sabicas, quienes hicieron su debut en Nueva York en 1941. Esta fecha marcó un hito en el desarrollo del flamenco allende las fronteras españolas. Desde este momento, Nueva York se convirtió en uno de los centros internacionales del mundo flamenco. Algunos de los artistas que venían, también comenzaron a impartir clases de danza en sus viajes de gira como medio para aumentar sus ingresos y, como resultado, aparecieron los primeros bailaores americanos de talento suficiente como para actuar internacionalmente (Woodall 1992: 193-195). Gracias a la continuidad que estos artistas dieron a las esporádicas actuaciones de artistas españoles en gira, el flamenco se estableció como una fuente regular y constante, de relativamente fácil acceso para el público de las grandes ciudades, de exotismo español $y$ gitano, primero en Nueva York y posteriormente en el imaginario americano en general.

Mientras tanto, el flamenco no gozaba de su mejor momento en España, y muchos artistas decepcionados y presionados por la creciente escasez de oportunidades en su país natal comenzaron su éxodo a América. La dictadura de Franco resultó desastrosa para el arte y la cultura en general, pero incluso si aquellos artistas que venían a América sufrían la misma presión económica que el resto del país en los tiempos de la Gran Depresión de los años 30, se sentían inspirados por el público americano 
para expresar su duende (Koegler 1978). La diferencia de actuar en España y en el exterior en aquel tiempo era que en España, incluso aquellos artistas que conseguían oportunidades de actuación, se encontraban en un callejón sin salida, incapaces de crecer artísticamente en un entorno de opresión y censura (Johnson 1999: 38).

Mientras el baile flamenco padecía en España las consecuencias, primero de la inestabilidad política, luego de la Guerra Civil y finalmente de la dictadura, en los Estados Unidos se hacía cada vez más popular. Ya en 1915 Ted Shawn había coreografiado una danza española, y en 1920 presentó una suite de danzas españolas con Martha Graham como compañera (La Meri 1967: 25). La Argentina actuó en Nueva York en 1916 y 1917; más tarde, con la excepción de 1933, tuvo actuaciones regulares de 1928 a 1936 (Goldberg 1995: 236). Ángel Cansino, el padre de Rita Hayworth, enseñó danzas españolas a muchos americanos — desde danzas boleras hasta "regionales", incluyendo flamenco- y Guillermo del Oro, que originalmente había llegado a los Estados Unidos como artista en gira, había decidido quedarse y abrir su propio estudio de danza, dada la demanda existente. María Montero, quien se había hecho famosa por sus actuaciones de vaudeville, logró tal popularidad bailando flamenco que durante su estancia en Nueva York actuaba en tres sesiones diarias (Vega de Triana 1993: 39).

Así, el flamenco encontró en Estados Unidos el escenario perfecto para continuar su desarrollo comercial, mientras en España, y especialmente en Andalucía, mantenía su tradición en las condiciones más adversas, fundamentalmente a través de performances no oficiales, como juergas y reuniones privadas. Paradójicamente, por este mismo tiempo ya comenzaba a ser definido por la oficialidad como "la música española" por excelencia. Este doble desarrollo, crecientemente esquizoide, sería fundamental de la década de 1970 en adelante, especialmente en lo que al flamenco transnacional se refiere, ya que posibilitó la sustentación del flamenco teatral y comercializado - primero fuera y luego también dentro de España- en base a una tradición "genuina" que le servía de origen y alimento. La "diferencia sincronizada", sin embargo, creció al mismo tiempo y al mismo ritmo que creció la popularidad internacional del flamenco.

Cada vez más artistas, españoles y no españoles, se involucraron en giras artísticas por los Estados Unidos y abrieron escuelas de danza por todo el país. América en general, y los Estados Unidos en particular, se convirtieron en los centros "descentrados" de la danza española flamenca (Johnson 1999: 150).

Mariquita Flores, puede ser un buen ejemplo de artista a medio camino entre las fuentes "originales" del flamenco y sus desarrollos en Ultra- 
mar. La bailaora nació en España en 1917, pero emigró a Nueva York a la edad de tres años. Aprendió a bailar flamenco en los "clubes sociales" donde los emigrantes se reunían los sábados y donde algunos de ellos actuaban informalmente. Luego comenzó a actuar públicamente y su talento y expresividad la hicieron famosa. Su presencia era requerida cada vez que una película de las que Hollywood producía, sobre todo en los años 50, debía incluir un baile flamenco. Estas actuaciones en famosas películas eran frecuentemente descontextualizadas y cortadas, como sucedió en la primera versión de Blood and Sand, dirigida por Rouben Mamoulian en 1941, que originalmente había sido filmada para competir con Gone with the Wind.

Aunque los bailes flamencos nunca eran parte fundamental de los films, su presencia se hacía cada vez más constante debido a la buena aceptación que tenían entre un numeroso público. La carrera de Mariquita Flores se desarrolló no sólo a través de actuaciones públicas, sino a través de la escuela que formó, y en la que solía decir a los estudiantes que el mejor lugar para estudiar y aprender el baile flamenco eran los Estados Unidos, pero que también era imprescindible viajar a España para "captar el sabor" (citada en Johnson 1999: 150).

Es interesante resaltar que, mientras el baile flamenco se hacía cada vez más popular en la escena internacional, ni la guitarra ni el cante lograron nunca la misma aceptación ni popularidad. En los años 30 y 40, el baile español era enseñado en sus cuatro formas fundamentales -Escuela Bolera, Danza Española Regional, Danza Española Teatral y Flamenco (Draegin 1978: 66). Esta división se prolongó en diferentes maneras hasta los años 70, cuando la popularidad del flamenco sobrepasó claramente al resto de los bailes, que habían comenzado ya a ser relegados desde los años 50 (Ivanova 1970: 10). De los 60 en adelante, el flamenco se estableció no sólo como una forma artística extranjera de presencia regular en toda América, sino como una forma diferencial de arte específicamente española e hispanoamericana.

El caso de la guitarra es muy diferente. Tras los éxitos de Sabicas en Nueva York y en sus giras americanas, tras su emigración a México primero y a los Estados Unidos después, y tras las decenas de grabaciones que realizó, muchos americanos comenzaron a interesarse también por la guitarra, aunque ninguna escuela importante para su aprendizaje se estableció como había sucedido con el baile. Algunos de estos aficionados americanos viajaron a España para aprender y para experimentar en vivo la tradición andaluza y gitana del flamenco. Morón de la Frontera, en Sevilla, se convirtió en el principal centro de peregrinaje para ellos durante muchos años. Algunos de estos aficionados escribieron libros sobre 
su conocimiento y experiencias en el mundo flamenco, de gran éxito entre el público americano interesado. $\mathrm{Y}$ algunos incluso establecieron su hogar permanentemente en España, llegando a ser parte relevante de la escena local.

Estos peregrinajes a España, no sólo de guitarristas, sino también de bailaores, crearon una particular comunicación entre las escenas española y americana, poniendo en contacto los escenarios más tradicionales del flamenco, en los que el cante y el toque eran fundamentales, pero cuyos desarrollos se mantenían con altos y bajos, y la escena comercial, de éxito creciente. Sin embargo, esta comunicación estuvo siempre mediada por el hecho de que los artistas y aficionados en España tenían la oportunidad de un feedback directo de las fuentes flamencas, andaluzas y gitanas. Mientras tanto, en los Estados Unidos los artistas desarrollaban sus carreras no sólo aislados del entorno sociocultural del flamenco español, sino también de la cultura popular americana, ya que el flamenco en ningún momento fue parte del mainstream. Su aislamiento era doble y así los artistas americanos desarrollaron maneras específicas de interpretar y experimentar el flamenco. Con el tiempo, una escena diferencial flamenca se desarrolló en América y comenzó a influir en la escena española. Por ejemplo, las actuaciones de guitarra que más populares se hicieron en los Estados Unidos se caracterizaban por ser especialmente virtuosísticas, en lugar de favorecer la comunicación entre artistas y público, como era la norma entre los aficionados españoles. El hecho de que el cante nunca se desarrollara plenamente en la escena americana ha sido fundamental en la descontextualización del flamenco producida en los Estados Unidos. Las dificultades que caracterizan al cante flamenco son insuperables para la mayor parte de los aficionados no españoles, y la imposibilidad de comprender las letras y sus dinámicas expresivas han sido clave para que el cante no sea tan comercializable como lo es la danza o, en menor medida, la guitarra. Hoy en día, las actuaciones de guitarra sin cante son comunes también en España, y en gran medida esto ha sucedido por la atención internacional que virtuosos como Sabicas o Paco de Lucía han atraído sobre la guitarra solista. Sin embargo, mientras desarrollos como estos coexisten en España con otras formas flamencas más tradicionales, en los Estados Unidos son los únicos que tienen proyección pública.

\section{DEL AURA AL KITSCH}

Una vez que la escena flamenca americana comenzó a tener importancia en sí misma, desde la década de 1970, la popularidad del flamen- 
co también decreció en los Estados Unidos. Paradójicamente, el flamenco que llegaba mayormente al país comenzó a ser visto como un fenómeno demasiado comercial; en otras palabras, comenzó a perder su "aura" (Benjamin 1969). Tras la muerte del dictador, la situación también cambió en España. Durante cuarenta años los artistas habían tenido que actuar públicamente en sitios determinados, conseguir un carnet acreditativo de "artista" que las autoridades expedían, y modelar en ciertas maneras la expresión de sus sentimientos a través del flamenco para no amenazar la llamada "pureza del arte español". Sus actuaciones eran instrumentalizadas por la oficialidad para transmitir una falsa idea de unidad y homogeneidad. Con la democracia, aparecieron nuevas posibilidades para los artistas españoles: fusiones, experimentos, mezclas, colaboraciones... Para entonces, sin embargo, España ya no era el punto de referencia en la escena del baile. Norteamérica había tomado el primer lugar, tanto en número de escuelas (que ya se desperdigaban por ambas costas y a lo largo de los estados sureños), como en posibilidades profesionales para los bailaores flamencos (giras constantes, red de teatros, actuaciones coordinadas con escuelas y cursos magistrales...). Este desarrollo había comenzado, además, a influir en la escena comercial española.

Carmen Amaya había incorporado ya el zapateado rítmico y la vestimenta provocativamente masculina al repertorio femenino de baile gracias a sus actuaciones en el exterior, y la nueva escuela de baile que ella inició creció sobre todo fuera de España. También los bailaores masculinos comenzaron a ser más libres en sus movimientos de manos y brazos, porque fueron capaces de desarrollar sus bailes fuera de España, donde las convenciones eran más rígidas (Johnson 1999: 151).

En definitiva, el baile flamenco que se había desarrollado en los Estados Unidos fue tan popular entre el público, y tan exitoso comercialmente durante las décadas previas al establecimiento de la democracia en España, que los artistas españoles desaparecieron como punto único de referencia en el imaginario americano, pasando a compartir preeminencia con otros artistas y profesores de baile locales. Con ellos, también el "aura" que inicialmente habían transmitido, ya que cada vez más los artistas modelaban sus actuaciones para encajar en el nuevo sistema comercial que les daba cabida. No es sorprendente entonces que los aficionados americanos que habían viajado a España para "conseguir el sabor" y que se habían empapado de la tradición en Andalucía para comprender mejor el flamenco, comenzaran a sentir nostalgia cuando cada vez más artistas españoles emulaban las actuaciones comerciales estadounidenses para poder asegurarse giras en este país. La distancia entre las fuentes tradicionales del flamenco y sus vertientes comerciales había crecido de manera dema- 
siado dramática y ya no apelaban al mismo tipo de público tampoco en los Estados Unidos.

Muchos aficionados no españoles dicen que el flamenco fuera de España carece de "duende", y esta carencia general en el flamenco transnacional - tanto el que se realiza en España como fuera de ellaha sido compensada con una mayor espectacularidad y una incorporación más libre de elementos ajenos al mundo tradicional del flamenco a nivel formal. El virtuosismo es apreciado por muchos aficionados como una de las principales características de la guitarra flamenca, mientras que para otros es la principal causa de su ruina. En un momento determinado, como sucede con otras tradiciones culturales que siguen desarrollos diferentes y simultáneos, la nostalgia por el "original" persigue los progresos de las nuevas formas como un lastre, condicionándolas y poniendo el toque de añoranza en cada novedad, haciendo que los nuevos fenómenos resulten fragmentados e incompletos por su original dependencia de un modelo que, por su misma naturaleza, no es comercializable ni exportable. En palabras de Olalquiaga:

Like fallen angels, objects lose or rather ruin their auras upon descent, arriving with little more than a crumbling, dusty shadow of their once iridescent haloes. Deprived of supernatural immunity, the shaken-down aura falls prey to all the vicissitudes of earth-bound things: it can be touched, traded, copied and tampered with; it is but a fragment of its former existence. It is kitsch (1998: 95).

Es en este momento de añoranza inconsolable cuando aparece el toque kitsch y se consolida como una de las características fundamentales del flamenco transnacional más contemporáneo, junto con la nostalgia. Las razones vendrán determinadas porque el flamenco como fenómeno será desarrollado para ser interpretado en entornos no flamencos utilizando productos formales desarrollados para ser comercializados. Sin embargo, se les infundirá el aura de las actuaciones tradicionales en entornos familiares, para validarlos artificiosamente. Este es un fenómeno, como el kitsch, plenamente moderno. No hay más que recorrer los títulos con los que las actuaciones flamencas se presentan en Nueva York: "Pasión Flamenca", "Flamenco Puro", "Fuego Flamenco"...

Otra razón de esta "kitschificación" aparecerá porque el aspecto visual está hipertrofiado en la expansión transnacional a costa de otros aspectos que son más importantes pero más difícilmente reproducibles —como el "duende", o el "misterio". Un magnífico ejemplo lo constituye una de las publicidades que anuncian flamenco en internet, en la que una foto de un flamenco rosa, un pink flamingo, símbolo kitsch por excelencia de la cultura popular, aparece tachada y acompañada de la frase: "It is Flamen- 
co, not Flamingo". Será la impotencia de reproducirlo fielmente "fuera de su entorno natural" lo que hará que se desarrolle a través de las particulares formas de la nostalgia como fenómeno kitsch.

En España estas dos esferas del mundo flamenco, la tradicional y la comercial o "turística", rara vez se confunden, porque aquí la tradición tiene un peso específico, especialmente desde los años 80, gracias al apoyo oficial que ha recibido. Repasando la historia del flamenco, sin embargo, hemos de admitir que comenzó a perder ese "aura" cuando los primeros artistas comenzaron a ser pagados en los cafés cantantes, es decir, cuando comenzó la comercialización. A menudo son los mismos artistas los que actúan en ambos escenarios, los familiares y los públicos, cambiando sus repertorios y puesta en escena para la ocasión. A pesar de ello, el mundo tradicional que dio lugar al flamenco sobrevive y continúa su existencia, cada vez más valiosa y frágil para los aficionados, de manera paralela al mundo comercial, e interactuando con él constantemente. Incluso en un tiempo donde no hay virtualmente ningún fenómeno intocado por la modernidad, el mundo tradicional del que se alimenta el flamenco ha conseguido permanecer vivo y diferencial. Es por esta razón por la que sigue siendo efectivo como alimento y punto de referencia para el flamenco comercial, y también por lo que, a pesar de sus infinitas variaciones y mestizajes, "lo flamenco" sigue teniendo una personalidad distintiva.

En la escena transnacional la situación es diferente. El flamenco desarrollado en Ultramar ha creado sensibilidades dependientes de las fuentes "originales" pero no las ha actualizado, porque esas fuentes no están vivas en el entorno geográfico en el que se desarrolla. Como fenómeno cultural, el flamenco americano está mediatizado, tanto por sus particulares circunstancias en los Estados Unidos, como por la diferencia irreconciliable entre ellas -actuaciones públicas y juergas privadas - y la fuente de la que originalmente vivieron, que nunca pudo sobrevivir allende las fronteras andaluzas. La expansión transnacional produce fenómenos kitsch en el mundo del flamenco porque éste no puede vivir en otros lugares si no es a través del mantenimiento del mito de la "autenticidad" como referencia, y porque como mito o como realidad, esta "autenticidad" no es exportable. "En esta contradicción intrínseca entre el deseo y la imposibilidad de su realización es donde las dialécticas del kitsch tienen lugar", moviéndose entre un pasado irrecuperable y un presente fragmentado, "viviendo la certidumbre de su propia imposibilidad" (Olalquiaga 1998: 68; traducción mía).

El caso del flamenco americano ha de entenderse como dependiente en igual medida del mundo ancestral del que deriva su existencia, y de 
la comercialización existente en las escenas locales donde se asienta, en las que su espectacularización es condición sine qua non. Su diversificación como fenómeno corre paralela a la estandarización y esclerotización de los cánones por los cuáles se rige.

Paradójicamente, el hecho de que el flamenco se haya hecho transnacional es lo que ha posibilitado que sus fuentes tradicionales devinieran distintivas por primera vez. Según la progenie creada por estas tradiciones crece y se multiplica de manera no siempre previsible, la tradición vuelve a ser rescatada, reificada e infundida de "aura". Como algunos intelectuales han notado (Benjamin 1969; Olalquiaga 1998), el "aura" comienza a existir en el mismo momento en el que desaparece. En una ironía del destino, el flamenco andaluz fue dotado de ese "aura" sólo cuando ésta fue disuelta en la multitud de fenómenos y desarrollos transnacionales que, paradójicamente, nacieron deudores de ella.

\section{BIBLIOGRAFÍA CITADA}

“La Meri” [Russell Meriwether Hughes]. 1967. Spanish Dancing. Pittsfield, MA: The Eagle Printing and Binding.

Álvarez CABAllero, Ángel. 1981. Historia del cante flamenco. Madrid: Alianza.

BAUdRILLARD, JEAN. 1994. El otro por sí mismo. Barcelona: Anagrama.

Benjamín, WALTER. 1969. "The Work of Art in the Age of Mechanical Reproduction", en Illuminations: Essays and Reflections: 217-51. Ed. de H. Arendt. NuevaYork: Schocken Books.

BOIS, MARIO. 1994. Carmen Amaya o la danza del fuego. Madrid: Espasa Calpe. CABALlERO BONALD, JOSÉ M. 1997. Luces y sombras del flamenco. Barcelona: Lumen.

DRAEGIN, LoIs. 1978. "Spanish Dance in America: Fanning the Spanish Fever". Dance Magazine 52/4: 63-73.

ESCUDERO, VICENTE. 1947. Mi baile. Barcelona: Montaner y Simón.

FERNÁNDEZ-SHAw, CARlos M. 1987. Presencia española en los Estados Unidos. Madrid: Ediciones Cultura Hispánica.

García-CANClini, NÉstor. 2000. La globalización imaginada. México D.F.: Paidós.

GOLDBERG, MEIRA. 1995. Border Trespasses: The Gypsy Mask and Carmen Amaya's Flamenco Dance. Tesis Doctoral. Temple University, Philadelphia, PA.

Grande, FÉlIX. 1979. Memorias del Flamenco. Madrid: Espasa Calpe.

HANNERZ, Ulf. 1998. Conexiones transnacionales. Cultura, gente, lugares. Madrid: Cátedra.

Ivanova, ANNA. 1970. The Dance in Spain. Nueva York: Praeger Publishers.

JOHNSON, CAROLYNN HINE. 1999. Mariquita Flores and Victoria Flores Cook: Two prominent women in the development of American Flamenco Dance. Tesis Doctoral. Temple University, Philadelphia, PA.

KoEgler, HoRst. 1978. "An Interview With José Udaeta". Dance Magazine 52/4: 73-77.

MACHADO Y Álvarez, ANTONIO ("Demófilo"). 1975. Cantes flamencos. Madrid: Espasa Calpe. 
- 1981. Colección de cantes flamencos recogidos y anotados. Madrid: El Porvenir. MCGREw, ANTHONY. 1996. "A Global Society?", en Stuart Hall, David Held, Don Hubert y Kenneth Thompson (eds.), Modernity. An Introduction to Modern Societies. Oxford [U.S.] - Malden [U.K.]: Blackwell.

Mercé, ANTONia. 2000. "La Argentina": Flamenco and the Spanish Avant Garde. Hannover [U.S.]: University Press of New England.

Olalquiaga, Celeste. 1992. Megalopolis. Contemporary Cultural Sensibilities. MinneapolisOxford: University of Minnesota Press.

- 1998. The Artificial Kingdom. Nueva York: Pantheon Books.

ROBINSON, HARLOW. 1994. The Last Impresario: The Life, Times and Legacy of Sol Hurok. Nueva York: Viking Penguin.

Vega DE TRIANA, RitA. 1993. Antonio Triana and the Spanish Dance. Langhorne, PA: Harwood Academic.

Washabaugh, Christopher. 1996. Flamenco: Passion, Politics and Popular Culture. Oxford-Washington D.C.: Berg Publishers.

WOODALL, JAMES. 1992. In Search of the Firedance: Spain Through Flamenco. Londres: Sinclair-Stevenson. 